\title{
A MATERNIDADE: DESTINO E CARGA
}

\author{
Mariana Sbaraini Cordeiro
}

\begin{abstract}
RESUMO: Esse trabalho analisa o conto "La Pietá", de Cecília Prada (1972), focando o tema da maternidade em um espaço urbano, onde as dificuldades da cidade grande fazem emergir também os problemas da vida privada de uma mãe pobre que luta para que seu filho nasça vivo, apesar das circunstâncias serem totalmente adversas. A análise evidencia a falência não só da família, como também a do ser humano. Por ser um texto de autoria feminina, esse trabalho traz alguns conceitos sobre esse tipo de texto, e também aponta o percurso das lutas feministas. Como resultado, a Ginocrítica surge como uma possibilidade teórica para que o texto literário seja explorado.
\end{abstract}

PALAVRAS-CHAVE: Conto brasileiro. Literatura de autoria feminina. Maternidade. Feminismo. Ginocrítica.

\begin{abstract}
This paper analyses the short story "La Pietà", written by Cecília Prada (1972), focusing on the theme of motherhood in an urban area where the difficulties faced in a big city also arise the problems of the private life of a poor mother who fights for his son to be born alive, despite the adverse circumstances. The analysis highlights not only the failure of the family, but also of the human being. As it is a text written by woman, this paper presents some concepts of such writing, and also points the way that feminist struggles followed for. As a result, Gynocriticism emerges as a theoretical possibility that the literary text can be exploited.
\end{abstract}

KEYWORDS: Short story. Women writers. Motherhood. Feminism. Gynocriticism.

\section{INTRODUÇÃO}

A sublimação do sentimento materno resulta no mito que envolve todas as mães, pelo menos as do mundo ocidental, desde o final do século XVIII, como se todas as mães amassem seus filhos de uma mesma maneira e jamais fossem capazes de lhes infligir algum mal. Mas é esse mal que tem suscitado tantas pesquisas nos mais diversos campos do conhecimento e, mais recentemente, pelas artes. Tal assunto acabou ficando silenciado, principalmente nos anos 1980, a década na qual a mulher queria fugir de qualquer resquício do Essencialismo Biológico, aquele que postulava que a "woman has an essence, that woman can be specified by one or a number of inborn attributes which define across cultures and throughout history her unchanging being and in the absence of which she ceases to be categorizes as a woman" (SCHOR, 1995: 46). Porém, quando o assunto era tratado, mostrava uma mãe totalmente 
desvirtuada de seu estereótipo ideal, personificando mães que mais se pareciam com as madrastas dos contos de fada. Olga Rinne fala desse estigma feminino ao reviver o mito de Medeia: "Medéia toca em nossa cultura, em áreas repletas dos mais profundos tabus e de que, em nós também, estas áreas estão enraizadas em tabus: a raiva, a ira, a oposição, o poder, a violência e a vingança não cabem na nossa imagem de feminilidade”. Esse conflito gerado pela forma patriarcal de ser mãe contribui muito para a "era da culpa materna". Rinne afirma que: "muitas mulheres rejeitam a imagem patriarcal da feminilidade e buscam uma nova compreensão de si mesmas, sentindo-se hoje como se fossem estranhas e estivessem exiladas no mundo em que nasceram" (2005: 13). A autora ainda sustenta que a identificação da mulher moderna com a Medeia simbolizaria

o aspecto 'feminino sombrio', portador de valiosas energias, que só podem ser liberadas, no ego de uma mulher, quando esta ousa olhar para o interior dessa escuridão e ir sem medo ao seu encontro [...] ela surge como a imagem oposta à mulher demasiado dócil e retraída criada pelo patriarcado, e símbolo da dignidade, sabedoria e competência femininas, que as mulheres atualmente procuram reconquistar. (2005: 14)

Sufocada pelos dogmas patriarcais, a mãe esteve reclusa por muito tempo no limite do privado. Garantir que essa mulher estivesse sempre pronta a parir e a cuidar de sua prole era a forma mais eficaz de limitá-la ao seu próprio espaço. Dona e refém ao mesmo tempo, é assim que muitas mulheres vivem até hoje. Pensar que a sua liberdade enquanto indivíduo foi conquistada há menos de um século pode até ser um motivo a se comemorar - e de fato foi uma grande conquista. Por outro lado, há situações que demonstram a própria mulher ainda muito arraigada aos ideais patriarcais. Há lugares onde a informação das conquistas das feministas ainda não chegou. A questão que fica é quanto custou a luta pela liberdade e se de fato ela foi alcançada ou acabou resultando em um plano frustrado cujas consequências nós mulheres sofremos até hoje.

A situação da mulher dentro do sistema patriarcal foi denunciada não só pela crítica feminista, mas também pela antropologia, sociologia e história, ao despertarem um olhar para a causa da mulher. A literatura compartilhou desses pensamentos e coube a ela mostrar de forma ficcional, mas não menos importante, a luta da mulher para se libertar dos grilhões que a subjugavam ao seu próprio lar. A pesquisa passa a ser relevante quando faz uma reflexão sobre de que maneira isso se torna ficção, por isso é imprescindível considerar o papel que as narrativas de autoria feminina tiveram para que, no mínimo, esse panorama fosse questionado. 
Pesquisar como a voz feminina se faz visível e audível na produção literária abre um mundo de possibilidade de estudo do texto literário portador de um discurso emancipador do sujeito feminino.

Especificamente no Brasil, tem-se que levar em consideração como conflitos sociais e culturais tiveram o poder de influenciar a produção literária. Se forem considerados os reflexos da industrialização do país juntamente com a Segunda Guerra Mundial, que demandou uma crescente mão-de-obra feminina, vê-se que a nação vivera um prenúncio de modernidade (era Juscelino) e depois foi embotada pelos anos de chumbo. Assim, é racional que todo esse contexto histórico-social tenha influenciado profundamente a produção artística brasileira.

Se a década de 1980 se abre para novas conquistas para os homens, para as mulheres se mostrou como o grande primeiro momento de romper com os ideais patriarcais. A década que exaltou o corpo ao máximo (MORICONI, 2000: 391) revelou uma produção literária de autoria feminina no mínimo audaciosa. Fruto de séculos de dominação do "macho" e mais vinte anos de imposições e perseguições militares, as mulheres gritaram o mais alto que puderam que aquele era o momento delas serem ouvidas. A professora Lúcia Osana Zolin afirma que essas mulheres que se lançaram no mundo da ficção tiveram uma mudança de mentalidade descortinada pelo feminismo em relação à mulher, "engendrando narrativas povoadas de personagens femininas conscientes do estado de dependência e submissão a que a ideologia patriarcal relegou a mulher" (2005: 277).

Toda essa liberação foi buscada até seus últimos limites. Passado o momento de efervescência, houve uma análise das consequências dessa liberdade desenfreada. Foi assim que a família passou a estar no centro das atenções dos textos literários de autoria feminina a fim de desvelar os conflitos do ambiente familiar, trazer para a sociedade discussões do que o solo privado andava fazendo. Vianna e Guidin afirmam que na literatura há temas que mobilizam mais mulheres que homens:

Em geral, são aspectos referentes ao cotidiano doméstico, a habilidades, afazeres e percepções femininas do entorno familiar; são recorrentes a visão perturbadora do pai, do marido, do amante - do ser masculino em geral. É frequente a memória peculiar que as mulheres carregam de suas dores e das dores do mundo bem como a apreensão das coisas míninas e desimportantes, das quais não raro conseguem extrair efeito simbólico inesperado e incomum. (2003: 7) 


\subsection{QUEM CONTA UM CONTO... ESQUECEU-SE DA MÃE}

A mãe considerada sagrada, atrelada à imagem da Virgem Maria, permeou o pensamento da sociedade ocidental até que, depois de uma liberação não só do corpo, mas, sim, do sujeito mulher, surge a Eva e para esta, a família e os filhos vem em segundo lugar. Primeiro seria a sua busca de felicidade, através da carreira, de vários relacionamentos amorosos, do seu corpo, da sua beleza. Mas então por que essa Eva não é mais feliz que aquela Maria presa a uma ideologia patriarcal? Para buscar uma resposta para esse questionamento, rever como os encaminhamentos feministas evoluíram, até o presente, pode ajudar.

Um ponto que preocupava as feministas da metade do século passado era como se diferenciar dos homens e onde buscar fundamentação para se definirem. A feminilidade, então, chegou a ser postulada pela capacidade natural de procriação da mulher, o que biologicamente seria o elemento fundamental. Mas tal definição não foi suficiente. Simone de Beauvoir questiona essa premissa com a frase que acabou sendo um mote do Feminismo: "Ninguém nasce mulher: torna-se mulher" e continua atribuindo um papel relevante para a cultura nessa questão ao afirmar que "[n]enhum destino biológico, psíquico, econômico define a forma que a fêmea humana assume no seio da sociedade; é o conjunto da civilização que elabora esse produto intermediário entre o macho e o castrado que qualificam de feminino" (1980b: 9).

Pela possibilidade de a capacidade reprodutora vir a ser o que diferenciaria a mulher de fato do homem, a maternidade foi um tema polêmico para as feministas. A maneira de abordar tal tema seria a aceitação desse destino; então muitas delas ou se referiram à maternidade de forma muito superficial, ou deixaram de abordá-la, e se fizeram, muita vezes foi de maneira preconceituosa.

A opção de excluir a maternidade como tema literário ficou evidente. Parece contraditório, mas tal ausência mostra muito sobre a nova mãe que estava sendo representada na negação da sua vocação "natural". A mulher passou a ser representada com muita frequência como aquela que conseguiu sua independência financeira e obteve total autonomia sobre o seu corpo. É significativa a ausência de uma mãe carinhosa, que cuidava dos filhos, dona de casa primorosa e esposa sempre pronta a agradar o seu marido. Por representarem mais o domínio patriarcal, essas características foram renegadas e o outro extremo ficou em 
evidência - mães que abandonavam seus filhos e maridos para irem atrás de seu bem estar e, o que é muito interessante, sem peso nenhum na consciência. A literatura acabou por representar mães que declararam não gostarem de todos seus filhos da mesma maneira e houve aquelas que escolheram o aborto para que esse arrependimento não as acompanhasse para o resto de suas vidas.

Diante disso, a maternidade foi um ponto nevrálgico a ser tratado e ao fazê-lo, muitas temiam assumir que as mulheres teriam mesmo um destino a cumprir. Elas queriam ser reconhecidas como sujeitos ativos, sociais, políticos, assim como eram os homens, e não pela sua anatomia (ou destino biológico). Por esse motivo, a maternidade, que havia sido vista com auras de sagrado, ou como uma maneira de controle da sociedade patriarcal, foi silenciada. Hoje, estudos teóricos têm se preocupado em trazer à luz o tema da maternidade que ficou por tempo demais às margens do pensamento.

Esse comportamento da nova maternação suscitou questionamentos sobre esse inesperado papel da mãe na sociedade contemporânea. Assim como a mulher é repaginada, também o é o homem. Ideias como as de Engels, que o homem teria participação no processo de fertilização como o "plantador da semente", passam a ser questionadas e colocadas em xeque. A literatura, então, passa a participar do processo de construção do sujeito ativo da sociedade de forma efetiva. Para a realização desse estudo, foi necessário compreender como se deu, ao longo da história ocidental, a cristalização da imagem da mulher-mãe oprimida pelos ideais sociais, culturais e religiosos. A pesquisadora da maternidade, Cristina Stevens, atesta que assim como outras manifestações artísticas, a literatura busca representá-la pela própria mãe e que:

Podemos dizer que a revisão do conceito de maternidade tem sido uma preocupação relativamente recente por parte dos estudos feministas. Articulando formas alternativas de construir uma nova ideologia da maternidade nos espaços vazios dos discursos hegemônicos [...] buscam entender o sentido da maternidade, da gravidez, do parto, dos cuidados com a criança, a partir da perspectiva/testemunho da mãe. (2006: 41)

Buscar tal compreensão contribui para a desconstrução/reconstrução do arquétipo de mãe e possibilita localizá-la no tempo e no espaço. O que se faz pertinente para os estudos literários é saber como todas as questões sociais, políticas, sociais e até econômicas transmitiram novos valores da maternidade. 


\subsection{E AS MULHERES CONTAM O QUÊ? - PROBLEMAS PÓS-1960}

As narrativas curtas dos últimos cinquenta anos no Brasil têm nomes representativos como Lygia Fagundes Telles, Lya Luft, Adélia Prado, Nélida Pinõn, Mariana Colasanti, Sonia Coutinho, Cecília Prada, Lucia Castello Branco, Tânia Jamardo Faillace, Ivana Arruda Leite entre muitas outras. Os contos dessas autoras falam de paixão, solidão, realização ou a busca dela. Temas como o ideal feminino, a preocupação de se afirmar enquanto mulher-sujeito e a sua luta contra o seu destino social e biológico são da mesma forma recorrentes. Há aquelas vozes mais libertárias que buscam romper com a divinização da mulher, que cobram uma postura condizente com seus anseios. Esses textos demonstram uma maior preocupação com os conflitos de ideologia e a condição da mulher objeto/abjeto lutando para ser agente de seu destino, sujeito de sua própria história e não mais aquele ser passível de manipulação.

Elódia Xavier (1991) assegura que, a partir de 1960, as narrativas de autoria feminina reuniam características comuns para retratar esteticamente a condição da mulher, vivida e transfigurada, passando a representar o mundo pela ótica feminina, o que seria diferente dos textos de autoria masculina. Xavier aponta que essa escrita teria como características o uso frequente da primeira pessoa, um tom confessional que chegaria a confundir o leitor “narradora ou autora? ficção ou autobiografia?” (XAVIER, 1991: 12), personagens em busca constante por sua identidade e de um espaço para autorrealização. Além dessas marcas do texto literário de autoria feminina, a mulher teria consciência de que o lar significava um lugar que tolhia seu acesso a um contexto social mais amplo e que "elas vivem dilaceradas entre o 'destino de mulher' e a 'vocação de ser humano"” (XAVIER, 1991: 12).

Obviamente que a literatura de autoria feminina é uma consequência dos movimentos feministas, por ter sido graças a eles que a mulher tomou consciência de seu papel e de como estava sendo obstruída para exercê-lo devido às imposições androcêntricas do nosso mundo. Esse espaço aberto propiciou um repensar sobre a condição da mulher nas mais variadas áreas; assim, a problemática da ideologia dominante passou a ser representada e questionada também pela literatura. Ao representar a mulher inserida nesse novo contexto, o lar passou a ser o centro das discussões para mais tarde ser totalmente renunciado, mostrando que a mulher poderia ocupar outros espaços além dele somente.

O próprio termo "literatura de autoria feminina" revela que houve, em um determinado momento da historiografia literária e da teoria literária, a necessidade de uma nomenclatura 
que distinguisse o texto produzido por uma mulher daquele produzido pelo homem. Ao usar essa nomenclatura, há evidência de que o texto de autoria feminina é distinto do de autoria masculina, mesmo que esse termo não exista. A sua inexistência não significa a sua ausência, pelo contrário. O descompromisso em não precisar ser denominado dessa maneira evidencia que toda (ou quase toda) produção literária era masculina e que, a partir de um determinado momento na história da literatura, as mulheres passaram a escrever. Diante disso é que o termo precisou ser aplicado por outras razões. Luiza Lobo afirma que

a literatura de autoria feminina precisa criar, politicamente, um espaço próprio dentro do universo da literatura mundial mais ampla, em que a mulher expresse a sua sensibilidade a partir de um ponto de vista e de um sujeito de representação próprios, que sempre constituem um olhar da diferença. (1997: 6, grifo da autora)

A mesma crítica ainda ratifica que será o distanciamento dos temas "domésticos" e "femininos", optando por aqueles de sua escolha, que resultará na mudança do cânone da literatura feminina. E seria a presença desses temas que permitiria uma intertextualidade com outros campos científicos, a saber, a filosofia, antropologia, sociologia, por exemplo. Porém, a prevalência e a imponência do texto literário devem ser um pressuposto a ser seguido pelos estudos literários, para que não haja a inversão do foco investigativo. O texto literário deverá ditar os apontamentos necessários para a sua compreensão dentro de um sistema cultural mais amplo. Luiza Lobo ainda descreve o que viria ser esse tipo de texto:

o texto literário feminista é o que apresenta um ponto de vista da narrativa, experiência de vida, e portanto um sujeito de enunciação consciente de seu papel social. É a consciência que o eu da autora coloca, seja na voz de personagens, narrador, ou na sua persona na narrativa, mostrando uma posição de confronto social, com respeito aos pontos em que a sociedade a cerceia ou a impede de desenvolver seu direito de expressão. (1997: 9, grifo da autora)

É certo que as mulheres passaram a ocupar definitivamente um lugar só seu, mas não porque não houvesse mulheres que escrevessem antes, mas, sobretudo, devido à linguagem instaurada por Clarice Lispector. O texto de autoria feminina passa, então, a se colocar politicamente contra a hegemonia masculina: "somente a partir de Clarice Lispector que não só a mulher começa a ocupar um espaço significativo na cena literária brasileira, como 
também começa a produzir uma obra que se peculiariza por uma série de razões já apontadas" (XAVIER, 1991: 15).

A alteridade passa a ser, para a literatura de autoria feminina, uma de suas abordagens centrais. Luiza Lobo adverte que essa forma de alteridade não é simplesmente considerá-la de acordo com a definição antropológica de Lévi-Strauss nem a de cunho filosófico, mas há a possibilidade de deslumbrá-la pelo viés psicanalítico "no confronto entre consciente e inconsciente, e, por conseguinte, na consciência de que não somos um eu total, sem arestas [...] mas um eu com fissuras, com desdobramentos. [...] alteridade do eu em relação a si mesmo é o ponto de partida da literatura contemporânea" (1997: 9). Propor-se a um estudo sob a abordagem feminista na literatura é considerar o outro que foi excluído, considerado estranho, por isso esse olhar sobre a mulher e os papéis que ela representa resulta em uma maneira de compreendê-la.

A mulher, como qualquer outro ser humano, passou a utilizar máscaras para tentar conviver melhor em sociedade; a diferença é que a mulher precisa de um leque maior dessas máscaras dentro do seu espaço privado - o de mãe, esposa, filha entre outras. Entretanto, a máscara de mulher como é concebida hoje foi a última a ser usada. Ou poderia se falar que, nesse caso, o espaço privado seria o único em que ela não precisaria usar máscara alguma? Creio que não. Nós mulheres acabamos por usar máscaras para nós mesmas quando lutamos contra o que somos, quando tentamos criar outra mulher para nos convencer de quem somos. Esse processo de busca por uma significação no mundo e para nós mesmas é constante na medida em que passamos nossa vida toda no intuito de nos conhecermos. Essas personae que vestimos, e fazemos isso de forma consciente, umas vezes mais e outras menos, dependem do grau de importância que cada mulher dá aos requisitos exigidos pelas mais diversas facetas da sociedade para ser aceita. Por exemplo, o comportamento que se espera que a mulher tenha na igreja é diferente daquele exigido pelo seu círculo de amizade; se vai à escola, como aluna veste outra máscara; o que se espera dela no trabalho determina outro tipo de máscara que deve ser usada. Essa multi-identidade tem revelado, na verdade, uma total falta dela. A ausência de autenticidade nos momentos em que o sujeito precisa se mostrar fica entre seguir a norma que todos seguem ou correr o risco de ser diferente e sofrer suas implicações. No âmbito privado também é assim - quanto mais representações sociais, maior será o guardaroupa de máscaras. 
No campo da literatura, a mulher para ser aceita como escritora e ter certo prestígio precisou se imbuir das marcas que lhe garantiriam ser aceitas pelo cânone, como bem mostra Lilian de Lacerda em sua obra Álbum de leitura (2003). Por isso, o estudo da nova autoria feminina a partir de 1960 se justifica, uma vez que o termo "autoria feminina" não se aplica a todas as obras escritas por mulheres. Foram somente as desse período em diante que se propuseram a tirar as máscaras, a buscar uma marca de alteridade que as distinguisse do discurso dominante, nesse caso o do homem, para marcar a sua identidade. Logo, é uma consequência pensar que nem todas as obras escritas depois daquela década por mulheres sejam pertencentes a este gênero - literatura feminina - pois, para isso, é necessário um constante despir, deixar para trás o todo, o comum, para marcar o novo, o silenciado, o que não fora dito. Consequentemente, o tema da maternidade revelado a partir daquele momento serve não só para que o homem conheça a nova mãe como também, e primordialmente, a própria mãe se conheça. A inclusão social da mulher passa por um momento de questionamento das posições que ocupa tanto no seu domínio público quanto no privado A professora Níncia Borges Teixeira afirma que essa inclusão social permite à mulher a "renovação da sua identidade em todos os setores, inclusive no campo literário. A produção literária de autoria feminina pretende falar da luta por espaço, reconhecimento, igualdade, mas, sobretudo, da reformulação da identidade feminina na sociedade" (2008: 33).

A criação desse espaço permite que a mulher-mãe se sinta segura em se despir de suas máscaras as quais filhos, marido, sociedade e ela própria exigiram por tanto tempo que ela usasse e, assim, ela se identifique com outras novas mães ao evidenciar as diferenças. Esse lugar onde as experiências subjetivas podem ser manifestadas é cheio de vazios e é nele que o discurso da literatura de autoria feminina encontra razão para existir. Preencher as lacunas da história, tanto a social quanto a literária, foi a maior marca de alteridade e o que determinou a permanência desse tipo de texto. Lembrando que tal empreendimento só foi possível graças às primeiras feministas que há mais de um século vinham lutando para que isso ocorresse, obrigando que houvesse mudanças sociais, culturais e políticas chegando ao máximo desse momento na década de 1960 afetando as mais diversas formas de pensar e por todo o mundo, inclusive no Brasil. Mesmo que aqui tenha tido interferências, esse momento aconteceu.

\subsection{LITERATURA E FEMINISMO NO BRASIL}


Para entender como a literatura passou a refletir as questões levantadas pelas feministas, se faz necessário uma inserção pelos caminhos da crítica. A primeira coisa percebida ao rever a história dos movimentos feministas é que havia um consenso sobre contra o que lutar, mas faltava uma visão imparcial de como fazer isso. Tal característica é evidenciada quando se listam as linhas seguidas por esse movimento: críticas negras, feministas marxistas, historiadoras literárias, críticas freudianas e lacanianas.

Mas mesmo faltando um consenso sobre o como fazer, essas contradições se mostraram fundamentais para a evolução do pensamento feminino. Se por um lado pode parecer que as divergências refletiam uma desorganização, por outro elas evidenciam a ânsia que a mulher tinha em lutar pelos seus direitos, mostrando ainda que entre as mulheres não existia um padrão, que nem todas eram iguais, como fora pregado por tanto tempo quando se colocava a mulher sob um estigma único.

Os ecos das manifestações feministas da década de 1960 repercutiram na crítica literária em meados do decênio seguinte, o que significa lembrar que eles chegam ao Brasil durante os anos de chumbo da ditadura militar. As consolidações dos ideais pós-estruturalistas encabeçaram o pensamento daquelas dispostas a relativizar não só a situação do sujeito naquele contexto social, como também havia chegado a hora de pensar uma maneira de representação desse pensamento e de sua significação para a mulher. Heloísa Buarque de Hollanda lembra que a organização do movimento feminista no país se deu durante a ditadura militar. Por ser uma forma subversiva de pensar, tal movimento se aliou a outras associações de esquerda como a setores progressistas da Igreja Católica, uma vez que eles eram contrários ao regime militar (2003: 16). Ironicamente, o movimento feminista brasileiro se alia àquele que foi o responsável pela sua repressão durante os séculos anteriores; entretanto, se não fosse assim talvez as ideias do movimento só conseguissem chegar aqui na metade da década seguinte, depois do movimento das "Diretas Já". Hollanda pressupõe que foi devido a essa aliança que o movimento feminista no Brasil não tratou de questões centrais para ele - aborto, liberdade sexual e divórcio - de maneira tão enfática e primordial como acontecera nos Estados Unidos e na França, mas que:

Por outro lado, a potencialização do espaço doméstico da família, ameaçado pela violência da repressão, e a politização do papel tradicional de Mãe, definiu vitórias políticas surpreendentes como o Movimento pela Anistia, encaminhado sob a bandeira inexpugnável da maternidade. Portanto, duas instituições conhecidas como basicamente conservadoras - a Igreja e a 
Família - tornaram-se arenas explosivas para a ação política radical das mulheres. (2003: 17)

No Brasil aconteceu o mesmo que nos Estados Unidos onde os movimentos feministas adentram facilmente o território das pesquisas científicas nas universidades, diferentemente do que havia acontecido na França. Nesse país, ainda há relutância para que isso ocorra, preferindo formas de organização independentes, desvinculadas da produção acadêmica. A área dos estudos literários encontrou nas reivindicações das feministas um campo fértil para desenvolver muitos estudos que precisavam recolocar a questão de gênero em foco. Essa necessidade é advinda da própria evolução do pensamento acadêmico e das novas urgências temáticas tratadas nos textos de autoria feminina.

Um ponto relevante discutido por Buarque de Hollanda é o desconforto gerado a qualquer iniciativa das mulheres pesquisadoras se autodeclararem feministas e aliarem seus estudos a esse tema. Essa dificuldade, principalmente por parte das profissionais liberais, intelectuais, artistas ou políticas, expõe uma imprecisão relacionada "aos mitos que regem a lógica das relações de gênero entre nós e, de forma mais geral, à especificidade das relações de poder no Brasil" (2003: 16). Talvez por ter aportado em meio às repressões militares, muitas dessas mulheres precisavam de um esforço duplo para levantar sua bandeira - mais do que uma autoafirmação, era necessário conquistar o lugar de sujeito ativo naquela sociedade. A mulher não precisava somente expor e impor suas reivindicações como acontecera em outras sociedades, aqui ela precisava ludibriar todo um sistema político repressor contrário a toda forma de expressão que fugisse do seu controle. Vale lembrar que manifestações de qualquer natureza eram proibidas.

O termo "feminista" poderia carregar conotações políticas e sociológicas, uma vez que era recorrente ele ser associado à luta trabalhista e pelos direitos iguais nas mais diversas esferas (LOBO, 1997). É possível imaginar as razões que levaram o movimento feminista brasileiro a se aliar com um de seus antigos algozes, a Igreja. Se não foram por essas razões, o pior é pensar que essas mulheres dos movimentos feministas e dos estudos que eles frutificaram foram mais temerosas em afirmar serem feministas para serem aceitas por uma sociedade ainda muito androcêntrica.

Entretanto, os estudos feministas hoje enfrentam desconfianças. Toril Moi questiona em seu artigo "I AM not a feminist, but...” (2006: 1735) se não haveria um problema com a teoria feminista hoje e se ele não estaria atrelado ao fato da teoria estar muito arraigada à tradição 
pós-estruturalista, cujos paradigmas teriam chegado à exaustão. Para a professora, "We are living through an era of 'crisis' [...] an era in which the old is dying and the new has not yet been born". (2006: 1735). Esse paradigma acentua que a teoria feminista é sustentada pelo feminismo e que esse campo do saber tem vivido nos Estados Unidos uma crise desde 1990 devido ao fato de muitos se negarem a assumir o rótulo de feministas.

Essa preocupação sempre houve no Brasil como já foram expostas acima as possíveis razões. Porém, nos Estados Unidos ela foi gerada por aquelas que se negavam a levantar a mesma bandeira das feministas mais radicais, entre as quais, as mais rejeitadas são a repulsa que sentiam pelo homem e por considerarem todas as mulheres como vítimas do sistema e o radicalismo em favor do aborto. Moi credita a essas características radicais a responsabilidade pelo resultado visto hoje: "feminism has been turned into the unspeakable F-word, not just among students but in the media too". (2006: 1739).

Refletindo sobre os temas tratados pelas diversas mídias e pelas universidades, Moi aponta um declínio dos que se referem ao feminismo e um aumento daqueles que revelam como é difícil para a mulher combinar trabalho e maternidade e como as novas mulheres tentam se libertar daquele feminismo dogmatista da geração de suas mães. A mesma autora ainda aponta que tanto a crítica quanto a teoria feminista colaboraram para que a imagem cultural do feminismo fosse melhorada e diz mais: "If feminism is to have a future, feminist theory - feminist thought, feminist writing - must be able to show that feminism has wise and useful things to say to women who struggle to cope with everyday problems" (2006: 1739). Para ela, esses textos, tanto literários quanto teóricos, devem tratar de temas do cotidiano das mulheres e que sejam dirigidos tanto para uma dona de casa quanto para uma "profissional de filosofia”. Ela faz essa consideração ao refletir sobre como a obra de Simone de Beauvoir conseguiu ter tanta repercussão. Em outra direção, Luiza Lobo também considera importante tratar temas próprios da vivência feminina, porém,

O cânone da literatura de autoria feminina se modificará muito se a mulher retratar vivências resultantes não de reclusão ou repressão, mas sim a partir de uma vida de sua livre escolha, com uma temática, por exemplo, que se afaste das atividades tradicionalmente consideradas 'domésticas' e 'femininas' e ainda de outros estereótipos do 'feminino' herdados pela história, voltando-se para outros assuntos habitualmente não associados à mulher até hoje. (1997: 7) 


\subsection{UMA POSSIBILIDADE: A GINOCRÍTICA EM PROL DOS ESTUDOS FEMINISTAS}

Ao estudar o percurso das lutas feministas, suas consequências no mundo e no Brasil, é fácil perceber a sua forte influência no campo dos estudos literários. Com a eclosão da produção literária de mulheres juntamente com o auge do feminismo, a teoria literária encontrou nessas manifestações um profícuo material que vinha ao encontro das necessidades que tais textos exigiam. Uma vez que as teorias existentes não davam mais conta das novas narrativas, as teorias feministas surgem na tentativa de suprir essa lacuna.

Elaine Showalter é contrária à crítica revisionista por acreditar que o principal problema de tal forma de crítica é ser construída sobre modelos já existentes e, sobretudo, por esses modelos serem androcêntricos. Como ela mesma diz, "[n]onetheless, the feminist obsession with correcting, modifying, supplementing, revising, humanizing, or even attacking male critical theory keep us dependent upon it and retards our progress in solving our own theoretical problems" (1981: 18). A posição contrária de Showalter explicita que o revisar de teorias já existentes não contribuiria para nenhum aprendizado novo. Para exemplificar esse processo, ela se refere à crítica francesa que elegeu Lacan como o "ladies man", continuando a se pautar nas correntes masculinas. Para não incorrer nesse risco, a autora busca uma forma de crítica que seja genuinamente centrada na mulher, na qual prevaleça a experiência feminina: "but we need to ask much more searchingly what we want to know and how we can find answers to the questions that come from our experience" (1981: 184).

Para Showalter, há três grandes linhas seguidas pela crítica feminista - a francesa, inglesa e a americana - e elas se distinguem pela base que sustenta essas linhas e, consequentemente, os temas salientados por cada uma. A linha francesa, cuja base é marxista, psicanalítica e desconstrucionista, procura salientar a repressão feminina apoiada nos estudos de Freud, Lacan e Derrida. É essa linha que apoia a existência de uma écriture féminine, na qual estariam as inscrições do corpo e as diferenças na língua e no texto de mulheres. As representantes mais expressivas dessa forma de pensar são Julia Kristeva, Hélène Cixous e Luce Irigaray. A linha inglesa não se difere muito da anterior, pois é igualmente de base marxista e incorpora o feminismo francês; assim, procura evidenciar a opressão que a mulher sofre através da interpretação textual e também tem o foco na escrita das mulheres. A última, a americana, tem seu foco no texto literário procurando evidenciar a expressão da mulher na literatura. Mesmo que haja certas discrepâncias entre elas, Showalter resume: "All are 
struggling to find a terminology that can rescue the feminine from its stereotypical associations with inferiority" (1981: 186).

A preocupação das correntes feministas era se constituir, por isso a crítica feminista, durante a década de 1970, precisou reivindicar um lugar inusitado de fala. Toda essa ânsia por criar algo inteiramente feminista marca a voz da teoria buscando se estabelecer, mas logo o resultado mostrou que não seria corrigindo, modificando ou atacando a crítica masculina que as pensadoras daquele momento resolveriam seus próprios problemas teóricos.

Elaine Showalter expõe que há duas formas de crítica feminista. A primeira leva em consideração a mulher como leitora, pois ao entrar em contato com um texto produzido pelo homem, a mulher-leitora consegue tomar consciência dos seus códigos sexuais, a qual Showalter chama de feminist critique e que como outras formas críticas, ela é

historically grounded inquiry which probes the ideological assumptions of literary phenomena. Its subjects include the images and stereotypes of women in literature, the omissions and misconceptions stereotypes of women in literature, and fissures in male-constructed literary history. (1979: 25)

O segundo tipo de crítica feminista considera a mulher como escritora por ser ela que produzirá os significados textuais imbuídos da história, temas, gêneros e a própria estrutura literária utilizada. Essa forma de crítica parte do pressuposto de que "its subjects include the psychodynamic of female creativity; linguistics and the problem of a female language; the trajectory of individual or collective female career, literary history; and, of course, studies of particular writers and works" (SHOWALTER 1979: 25).

Como resultado desse processo de formação de uma teoria feminista, o foco das investigações mudou seu olhar, ocupando-se das produções literárias escritas por mulheres. Durante essa reviravolta, Showalter desenvolve a segunda forma da crítica feminista que era mais de seu apreço:

the study of women as writers, and its subjects are the history, styles, themes, genres, and structures of writing by women; the psychodynamics of female creativity; the trajectory of the individual or collective female career; and the evolution and laws of a female literary tradition. (1981: 185)

Ao fazer tais considerações, Showalter adapta do francês o termo la gynocritique para gynocritcs por não haver na sua língua um termo equivalente. O propósito de tal crítica é estabelecer uma abordagem para a análise do texto literário produzido por mulheres, 
desenvolvendo novos padrões para o estudo da experiência feminina como forma de não mais ter que se adaptar aos modelos já existentes. No entanto, Showalter não é radical como muitas de suas compatriotas e partícipes do feminismo. Ela considera a possibilidade de usar um referencial teórico já estabelecido, e geralmente masculino, desde que as questões estejam centradas em representar e questionar a posição assumida pelas mulheres, ou melhor, destinadas a elas. A crítica proposta pela teórica é comparada aos estudos etnográficos, porque, assim, é possível compreender melhor os papéis que a mulher representa ao considerar o seu próprio ponto de vista.

A ginocrítica considera pesquisas no campo da história, antropologia, psicologia e sociologia, pois "have developed hypotheses of a female subculture including not only the ascribed status, but also the occupations, interactions and consciousness of women" (Showalter, 1979: 28). Tal empreitada não deixa de considerar as incursões políticas, sociais e pessoais que podem determinar as escolhas literárias da autora. Showalter atenta para a necessidade de abranger, também, a subcultura produzida pelas mulheres para que os temas e as estruturas literárias sejam compreendidos quando relacionados à tradição literária vigente.

Assim, por ser uma forma de crítica que oferece muitas oportunidades teóricas, a ginocrítica tem a seu favor a vantagem do crítico literário não ficar preso às teorias restritivas, podendo analisar como a escrita feminina tem sido considerada e como a condição da mulher influencia a produção dos textos dessas autoras. Para defender sua proposta teórica, Elaine Showalter afirma: "but we have the opportunity, through gynocritics, to learn something solid, enduring, and real about the relation of women to literary culture" (1981: 186). Ao fazer uso dos quatro modelos de diferença - biológico, linguístico, psicanalítico e cultural - a ginocrítica possibilita definir e diferenciar "as qualidades da mulher escritora e do texto da mulher” através dos modelos de cada escola de crítica feminista ginocêntrica.

Para Elaine Showalter, a crítica cultural se sobressai por proporcionar "a more complete and satisfying way to talk about the specificity and difference of women's writing than theories based in biology, linguistics, or psychoanalysis" (1981: 197). A prevalência da crítica cultural é defendida também por incorporar tanto ideias acerca do corpo, da linguagem e da psique feminina, sobretudo relacionando aos contextos sociais. Todas as ações da mulher estão intimamente ligadas aos seus ambientes estabelecidos culturalmente, como atesta ainda Showalter: 
Nonetheless, women's culture forms a collective experience within the cultural whole, an experience that binds women writers to each other over time and space. It is in the emphasis on the binding force of women's culture that this approach differs from Marxist theories of cultural hegemony. (1981: 197)

Para que seja possível a leitura de um texto literário pelo viés da teoria cultural, é importante pensar que a mulher tem papéis distintos dos homens. Apesar de fazer parte do mesmo grupo cultural global, as mulheres e suas ações no passado precisam ser estudadas considerando seus gostos, comportamentos como frutos do ambiente ao qual pertenciam. As mulheres têm sua própria cultura, mas ela está inserida em um modelo global que a abrange e serão as intermediações entre essa cultura particular com as demais que permitirão que o estudo de gênero não considere a esfera feminina isoladamente, uma cultura à parte de todo o resto. Pelo contrário, a mulher precisa encontrar a sua especificidade até dentro do seu grupo de mulheres que podem compartilhar os mesmos pensares, mas mesmo assim ela será um indivíduo único que marca a sua passagem. Se nesse caminho ela encontrar divergências entre seus pares, a forma como ela lidará com elas é que se sobressai nos estudos da crítica cultural.

Como recomendado por Showalter (1981: 202), para um estudo de crítica cultural é preciso que o locus cultural da identidade literária feminina seja delineado, situar as escritoras de acordo com as variáveis da cultura literária a qual pertencem como também levar em consideração os modos de produção e de distribuição, as relações entre autor e público, arte de elite e popular, por fim, as hierarquias de gênero.

Ao ser considerada tal abordagem para a análise que virá a seguir, penso que o texto literário possui dois discursos: um dominante e um silenciado. Medir a intensidade de cada pode resultar em uma análise que descobrirá o discurso velado pelo discurso dominante. Ou também, de forma mais escancarada, é possível que o velado já não o seja mais. Assim, buscar compreender como o tema da maternidade ganhou ou perdeu importância social no texto literário e suas possíveis razões para que isso ocorresse só será possível ao situá-lo cultural e historicamente.

A possibilidade de uma abordagem cultural proposta pela ginocrítica vem ao encontro das questões primordiais do meu trabalho. Tal abordagem permite, e de certa maneira exige, que se leve em consideração como a mulher concebe seu corpo, suas funções sexuais e a função reprodutiva levando em conta seu ambiente cultural, pensando que suas escolhas sempre são frutos de forças culturais. 


\subsection{AS POBRES MÃES POBRES}

A mãe pobre não é um tipo materno muito comum na literatura de autoria feminina pós1960. Talvez, o que justifique tal ausência sejam as muitas produções literárias de cunho social, produzidas durante a segunda fase do Modernismo. Depois de muitos anos em que a literatura teve um compromisso social de denunciar as mazelas do povo brasileiro com autores como Jorge Amado, Raquel de Queiroz, Graciliano Ramos, a geração seguinte tomou outro rumo. Até mesmo aquelas autoras que participaram (mesmo sendo em número pouco expressivo) da Semana de Arte Moderna pareciam distantes do projeto modernista. Constância Lima Duarte aponta que isso ocorrera porque as escritoras daquele tempo “estavam envolvidas em outro projeto - não necessariamente estético - mas principalmente ideológico, visando à emancipação da mulher" (2011: 45), eram escritoras que precisavam se voltar para questões mais urgentes, como "corrigir o atraso social e intelectual em que se encontrava a mulher brasileira" (2011: 46). Notadamente, o estudo de Duarte é muito relevante por apontar que, mesmo em meio à efervescência do início do Modernismo, as mulheres já legislavam em causa própria.

Outro aspecto relevante foi o processo de urbanização pelo qual passava o país, mais acentuado depois de 1950. Isso fez com que o cenário urbano se tornasse majoritário na literatura brasileira assim como a representação de uma nova tipificação social. Outra questão faz referências a tendências da literatura de autoria feminina, que sendo esta muito mais introspectiva, subjetiva da forma de sentir feminino, as questões sociais foram relegadas a um segundo plano, ou simplesmente não apareceram. O que não deixa de estabelecer um paradoxo, pois se com uma nova configuração feminina a mulher passar a sair mais, a ter acesso ao conhecimento e ao mercado de trabalho, seus questionamentos passam a refletir os conflitos da nova forma de ser mulher, mãe e esposa. Ao mesmo tempo em que em ela rompe com seu ambiente privado e se torna uma figura pública, seus textos são cada vez mais subjetivos. Mesmo sendo outros anseios e particularidades diferentes daqueles derivados das angústias econômicas, sempre há um interesse das narrativas por esta que faz parte de um substrato marcado pela categorização social em termos econômicos, a pobre mãe pobre.

"La Pietà" é um dos contos mais expressivos de Cecília Prada (2004: 169-181). Escrito em 1972 e publicado na sua coletânea $O$ caos na sala de jantar, em 1978, recebeu quatro 
prêmios literários no Brasil e no exterior. Ele já foi traduzido para o alemão, o italiano e o espanhol e em 2004 foi publicado no livro Estudos de interiores para uma arquitetura da solidão. Cecília Prada em seu conto, além de tratar a dor de se perder um filho, desnuda as mazelas sociais e culturais que uma mulher pobre vive.

O conto narra a história de Damiana, moça pobre que reside em um barraco na Favela da Rocinha no Rio de Janeiro. Abusada, desde os onze anos pelo irmão, Damiana espera um filho do marido João. Entrando em trabalho de parto, a jovem dirige-se ao hospital onde, depois de aguardar atendimento por longo tempo, mãe e filho morrem durante o parto. A autora intercala fragmentos de um texto jornalístico publicado em maio de 1972, no jornal Folha de S. Paulo com o título "Uma obra-prima desfigurada" que noticia a depredação da escultura La Pietà, de Michelangelo, na Basílica de São Pedro, em Roma. Como resultado, há um paralelismo que instaura um contraste entre o discurso jornalístico e o ficcional. A ambientação do conto denuncia a situação precária que uma mulher pobre e grávida tem de enfrentar: trajetos distantes até o hospital mais próximo, filas infindáveis, o descaso de médicos e enfermeiras. Nesse caso, a maternidade representada em "La Pietà" não assume o caráter sagrado inerente à imagem da escultura La Pietà.

A protagonista sofre muitas formas de violência, tanto físicas quanto psicológicas, ao longo da narrativa. Independente da gravidade, Damiana encara esses atos de violência como um castigo, colocando-se como merecedora de todos eles. Essa culpa que a protagonista carrega é explicada quando ela relembra um dos primeiros atos de violência que sofrera quando tinha apenas onze anos, o incesto: "Seu irmão. Tinha ciúme, sempre tinha, de qualquer namorado. Queria ela pra ele só, pegava ela de noite quando era menina, pegava, ela tinha medo e deixava, era puta era puta tinha dormido com o próprio irmão Deus castigava" (2004: 171). Abusada pelo irmão, Damiana se culpa por ter sentido um misto de dor e gozo. Como uma forma de expurgar seus pecados, a protagonista aceita todo o sofrimento para que possa ser purificada. A lembrança da violência cometida pelo irmão é seguida por outras que atestam que a personagem sempre foi abusada por todos os homens que conheceu. Essa rememoração é contracenada com o sagrado retomado a todo instante com flashes da notícia da depredação da escultura La Pietà.

Depois da surra que levou do irmão, a personagem precisa retornar ao centro médico de onde havia regressado há pouco. A distância é mais uma vez enfatizada e as dificuldades para percorrê-la também. No início da narrativa, Damiana percorre o trajeto de ônibus aos 
solavancos e agora ela faz o mesmo percurso dentro de um caminhão: "Os solavancos do caminhão muito pior que o ônibus mas vai levando vou chegar logo em tudo brutalidade bruto bruto tudo, os homens, o mundo" (2004: 171). A falta de vírgulas nessa descrição dá vida às palavras que parecem pular no mesmo ritmo dos solavancos do trajeto. A falta de pontuação também sinaliza a velocidade do que acontece à personagem, não lhe permitindo tempo para compreender e, assim como os inesperados solavancos da estrada, Damiana é pega de surpresa pelas intempéries da vida.

Nesse atendimento, Damiana é bem atendida pela primeira vez por um médico novo. Durante essa consulta, a bondade daquele médico faz com que a personagem busque em sua memória a primeira vez em que foi abusada pelo irmão. O choque entre o homem do presente e o do passado - seu próprio irmão - é marcado pela inércia da mãe de Damiana diante da pequena menina de apenas onze anos sangrando por ter sido violentada. Aqueles que deveriam lhe proteger se omitiram totalmente. Damiana tem mãe, mas não pode contar com ela em nenhum momento do conto e, desde muito cedo, essa mulher aprendeu que a violência da favela começa dentro de casa.

A imagem de Damiana é construída como uma La Pietà às avessas ao longo do conto, devido às incursões da notícia do que havia acontecido à escultura. Há trecho em que "o energúmeno atacou o rosto da Santa Virgem, quebrando o nariz e os olhos" (2004: 174) interrompe sua lembrança de abusos, despertada ao mesmo tempo em que é bem tratada pelo médico. A descrição da violação da escultura marca também a violação da personagem, deixando marcas não somente físicas.

A violência social que sobreveio foi maior quando ela entrou em trabalho de parto. Na terceira vez em que ela percorre a descida do morro, como uma via crucis, ela vai a pé. É nesse momento que dois taxistas ao vê-la naquelas condições lhe negam a corrida, mesmo ela tendo o dinheiro para pagar. Conseguindo enfim uma carona, a personagem vai, durante o percurso, descrevendo a visão que ela tem do mar, prenunciando o que haveria de acontecer ao seu menino. A dinâmica do mar, o ir e vir das ondas, ressalta seu caráter de que tudo que é levado por ele também pode ser devolvido, porém transformado. O mar vai, ao longo da jornada, assumindo cores diferentes: "verde palmeira', "azul calminho", depois "azul cor de menino", "cinza parado", mas também "cor da tristeza" quando ele é associado à imagem de morte que a água representa. Mais adiante ele é verde quando ainda há esperança de que o 
menino sobreviva. Porém, no momento de dor o "mar pode ser vermelho. Vermelho e quente como sangue" (2004: 176), assumindo seu sentido ambíguo, imagem de vida e de morte.

O duplo que a autora estabelece ao contrapor a atenção dispensada para os dois fatos causa mal estar: a multidão em volta da estátua despedaçada contrapondo à solidão da protagonista no hospital onde médicos e enfermeiras lhe ignoram; os pormenores do atentado atravessando a surra que ela leva; a descrição do autor do atentado, um húngaro, geólogo, que residia na Austrália interpondo a descrição do seu irmão bêbado. Dois criminosos, um pobre atacando a pobre, e o rico atacando a imagem esculpida em mármore revelam a inversão dos valores em um mundo dito cristão. Há uma visão crítica construída no momento que é estabelecido o paralelo entre os valores dispensados a Damiana, uma mulher, ser humano, e aqueles dispensados à imagem de pedra.

Enquanto o crime que o irmão cometera fica desconhecido de todos, graças ao silêncio de Damiana, o crime contra a figura da "Santíssima Virgem" tem repercussão mundial. Ao nascimento do filho morto, "[n]os braços rígidos, sem embalo, o filho, ela, ambos para sempre fixos - pedra. Para sempre" (2004: 181), no momento em que o noticiário avisa que a escultura será recuperada "num bloco de mármore de Carrara" (2004: 181), é conferida a ideia de transmutação. A escultura da santa ganha vida na morte, não só do menino de Damiana, mas, sobretudo, na morte da mãe. Damiana foi impedida de ser mãe por um sistema de saúde falido, por uma grande falta de valor humano, quando os médicos the deixam o dia todo em trabalho de parto sem assistência médica. Esta, aliás, trata a maternidade da mãe pobre como um castigo. As dores do parto são apontadas pelas enfermeiras de plantão como um sofrimento que todas têm de pagar como uma forma de débito a ser cobrado. São mulheres que não se condoem com a dor daquela que é sua próxima por ser pobre. A mulher pobre, no conto de Cecília Prada, não tem o direito de ser mãe. A santa de pedra ganha vida na narrativa, quando Damiana sofre com o mesmo sentimento sofrido por aquela mulher que a imagem representa: a perda de um filho.

Esse jogo do discurso jornalístico permeando o discurso literário acentua outras marcas da narrativa. Aquele assume um caráter público, enquanto o relato de Damiana parece ser amenizado pelo tom ficcional. A linguagem do conto também dita o tom da narrativa, a velocidade dos acontecimentos vai sendo acelerada conforme as dores do parto aumentam. Nesse processo também são maiores as interseções entre os discursos. Quando Damiana chega ao pronto-socorro, os trechos do texto literário e do jornalístico se aproximam muito. $\mathrm{O}$ 
intervalo entre as incursões de cada discurso são cada vez menores - a destruição da estátua e o parto de seu filho - muito mais próximas como as contrações uterinas antes do nascimento.

Damiana é a configuração mais comum de uma mulher pobre no Brasil. É muito jovem quando se torna mãe, quase uma menina reforçada pelas descrições de sua ingenuidade. Negra, pobre e semi-analfabeta, a situação social da personagem é caracterizada pouco antes da exaltação da escultura, podendo ser bem ilustrada com o seguinte fragmento marcado pela diferença da grafia das letras: "Na seção que tinha um nome esquisito Damiana soletrava a custo, gi-ne-co-lo-gi-a... obs-te... que é uma das mais celebres expressões da cultura humana." (2004: 170)

Trechos da notícia interrompem a narrativa estrategicamente sempre com o intuito de marcar a diferença do tratamento dispensado à escultura e a Damiana:

- Não é nada não, dona. Pobre tem de ajudar o outro. Eu pegava aquele desgraçado que fez isso e matava.

...O desalmado concentrou a sua fúria assassina na figura da Santíssima Virgem, cujo braço esquerdo demoliu completamente. (2004: 173)

O desalmado é quem proferiu os golpes contra a imagem e não aquele que, da mesma maneira, proferiu golpes contra uma mulher grávida. O sagrado nesse conto vai aos poucos sendo relegado à degradação da mãe. Ao lado do ato violento que se comete contra a imagem da mãe esculpida, vários tipos de violência que a personagem Damiana sofre são narrados: a surra que leva do irmão quando está prestes a dar à luz, o tratamento dos médicos e enfermeiras dispensado a ela, o descaso dos motoristas de táxi que lhe negam a corrida devido ao seu estado.

O texto é fragmentado pelas incursões de três tipos narrativos: a notícia, o narrador da história de Damiana e, diluído no entremeio desses, uma voz de alguém muito próximo do Papa. É esse último narrador que na noite do acontecimento estava na antecâmara pontifícia, quando ouviu um grito e pensou que o Papa tivera um pesadelo. Dois recursos visuais são utilizados para diferenciar essas duas narrativas paralelas da história de Damiana: a notícia é grafada em itálico e a participação desse novo narrador vem entre parênteses. Este surge ao relatar o momento que antecede o atentado contra La Pietà, parecendo ser uma testemunha ocular daquele crime.

Com as incursões desse novo narrador supõe-se que os diferentes discursos se tornam um só. Lá em Roma ele afirma: "De todos os cantos da terra. Um martelo. Enorme materno 
erguido, vinha" e em seguida descreve o que parecia ter sido o grito do Papa durante um pesadelo. No mesmo momento Damiana tenta resistir ao sono, temerosa de que algo ruim aconteça a seu bebê. Como havia tomado um calmante no pronto-socorro depois da surra de seu irmão, ela acorda assustada como o Papa: "A dor chegando dentro do sono de calmante. Partindo-a. Enorme machado caindo sobre ela. _ João! ... O menino...” (2004: 174). Nesse momento da narrativa, as ações ocorrem paralelas, no mesmo momento em que a estátua é depredada, Damiana começa a entrar em trabalho de parto. Os gritos das pessoas ao encontrarem a estátua e os gritos de dores da Damiana se tornam um só. Lá a estátua sofre os golpes de martelo e ao mesmo tempo Damiana grita aqui com as dores do parto.

Essa transmutação do sagrado da escultura para Damiana é enfatizada quando ela é preparada para uma cesariana de emergência:

todos os cinqüenta fragmentos das partes danificadas serão recolhidos $e$ catalogados e que...

... esquartejada, porco sangrado, animal, amarravam suas pernas, suas mãos, uma cruz, ela era a cruz.

... a estatua será reparada: 'Temos os fragmentos do braço e do nariz. Para o olho será muito mais difícil'.

... respira, respira fundo. (2004: 180)

O uso de reticências marca ainda mais a ligação de continuidade dos dois fatos em um só. Como é possível perceber com a leitura de excerto acima, as duas narrativas vão ficando muito mais próximas uma da outra, à medida que os trechos ficam menores e as interrupções de um discurso no outro acontecem com mais frequência, assim como acontece com as contrações de Damiana antes do parto. Esse parto marca a possibilidade de um renascimento da escultura ao Damiana se tornar mãe, porém como lhe é negado esse direito pelo descaso médico, Damiana é transmutada em estátua de pedra: "Nos braços rígidos, sem embalo, o filho, ela, ambos, para sempre fixos, duros - pedra. Para sempre” (2004: 181).

Damiana não compreende a dimensão do que está acontecendo a sua volta por ser uma menina ainda. Não é dita no conto a sua idade, mas há elementos que pontuam sua imaturidade, como a presença dos bichos de pelúcia. Ela é uma menina-mãe como também fora representada com feições infantis a própria estátua de Michelangelo. O nome Damiana, cujo significado é aquela que tem forte senso maternal, não deve ter sido escolhido aleatoriamente. 
A narrativa sobre Damiana termina assim: a mãe morta segurando também o filho morto nos braços, uma nova La Pietà. Tal cena não deixa de reforçar a incondicionalidade do amor maternal de que quando um filho morre a mãe morre com ele. No entanto, a cena final do conto fica a cargo da fala embargada do Papa Paulo VI: “"É o atentado mais grave contra a civilização e a cultura que se cometeu até agora. $\mathrm{O}$ mundo exige um castigo exemplar para o culpado"” (2004: 181). A contradição mais uma vez é instaurada pela repercussão dos fatos. Enquanto Damiana morre e ninguém fica sabendo, a notícia do crime em Roma se torna mundialmente conhecida. Impossível não se comover e se indignar com a inversão de tais valores, a sacralidade só existe no plano do ideal. A morte de seu filho acabou sendo o maior preço a ser pago, mas não suficiente, sua vida também foi cobrada. E nesse caso, o erro foi de quem?

Pode parecer forte, mas a mulher pobre não cumpre seu destino de fêmea ao ter filhos, ela tenta com eles se manter viva. Para essa mulher, é, sim, natural ter filhos, é natural cuidar deles da forma que for. Essa mulher realiza integralmente o seu destino biológico e para ela a maternidade é sua vocação natural, como dizia Beauvoir (1980b: 248). A mãe pobre não acredita que ter filhos seja o auge na sua carreira de fêmea, para essa mãe é sinônimo. A mãe pobre precisa acreditar na maternidade como instinto, mesmo que ele não exista; mesmo se ela sentir o mesmo que outras mulheres, independente da classe social, sentem quando seu filho nasce. Ela pode ter os mesmos medos e anseios, não sentir nada por aquele pequeno ser em seus braços, mas ela precisa acreditar que o amará devotadamente em prol da sua descendência. Se ela não acreditar no mito do amor materno, quem irá se preocupar com mais uma criança que só nasceu para aumentar as estatísticas? Como não lhe é dada opção, a mãe pobre é a única que precisa acreditar no mito do amor materno.

Se para a mãe desse extrato social a maternidade ainda tinha alguma razão sublime, ou até mesmo como uma forma de determinismo, isso ia contra o pensamento feminista. A opção de excluir essa temática das narrativas parece evidente, então. Narrativas como essa mostram que romper com um pensar cristalizado sobre a mulher-mãe só foi possível quando à mulher foi permitido o acesso à informação com sua entrada nas universidades, sua saída do mundo privado através do trabalho remunerado. Não há dúvidas de que o movimento feminista acarretou uma mudança radical sobre a condição feminina, mas enquanto essas conquistas não atingirem um contingente de mulheres de todas as classes sociais, a maioria das mulheres permanecerá reproduzindo o mito do amor materno como garantia de sobrevivência. 


\section{REFERÊNCIAS:}

BEAUVOIR, Simone de. O segundo sexo: A experiência vivida. Vol. 2. Rio de Janeiro: Nova Fronteira. 1980b.

DUARTE, Constância Lima. A literatura de autoria feminina no modernismo dos anos 30. In: Carlos Magno Gomes \& Lúcia Osana Zolin, orgs. Deslocamentos da escritora brasileira. Maringá: Eduem, 2011.

ENGELS, Friedrich. A origem da família, propriedade privada e do estado. São Paulo: Escala, s/d.

HOLLANDA, Heloísa Buarque de. O estranho horizonte da crítica feminista no Brasil. In: Flora Süssekind, org. Vozes femininas: gênero, mediações e práticas da escrita. Rio de Janeiro: 7letras: Fundação Casa Rui Barbosa, 2003.

LACERDA, Lilian. Álbum de leitura: memórias de vida, histórias de leitoras. São Paulo: Editora UNESP, 2003.

LOBO, Luiza. A Literatura feminina na América Latina. Revista Brasil de Literatura. Registros do Seplic (Seminário Permanente de Literatura Comparada, Departamento de Ciência da Literatura, Faculdade de Letras da UFRJ), n. 4, 1997.

MOI, Toril. "I AM not a feminist, but...": How feminism became the F-word. In: PMLA, 2006. p. 1735-41.

MORICONI, Italo (org.). Os cem melhores contos brasileiros do século. Rio de Janeiro: Editora Objetiva, 2000.

PRADA, Cecília. Estudos de interiores para uma arquitetura da solidão. São Paulo: DBA Artes Gráficas, 2004.

RINNE, Olga. Medéia: o direito à ira ao ciúme. 3.ed. São Paulo: Cultrix, 2005.

SCHOR, Naomi. This essentialism which is not one: coming to grips with Irigaray. In: Bad objects: essays popular and unpopular. Durham: Duke University Press, 1995. p.44-60.

SHOWALTER, Elaine. Towards a feminist poetics. In: Mary Jacobus, org. Women writing and writing about women. London: Crom Helm, 1979. p. 22-41.

Feminist criticism in the wilderness. Critical Inquiry. v.8, n.2, Writing and sexual difference. (winter, 1981). p. $179-205$.

STEVENS, Cristina. Maternidade e feminismo: diálogos na literatura contemporânea. In: Maternidade e feminismo: diálogos interdisciplinares. Florianópolis: Ed. Mulheres; Santa Cruz do Sul: Edunisc, 2006. 
TEIXEIRA, Níncia Cecília Ribas Borges. Escrita de mulher e a (des)construção do cânone literário na pós-modernidade: cenas paranaenses. Guarapuava: Unicentro, 2008.

Uma obra-prima desfigurada. Folha de S. Paulo 22 de maio de 1972. Disponível em http://almanaque.folha.uol.com.br/mundo_22mai1972.htm. Acesso em 31 janeiro de 2012.

VIANNA, Lucia Helena; GUIDIN, Márcia Lígia (Org.). Contos de escritoras brasileiras. São Paulo: Martins Fontes, 2003.

XAVIER, Elódia. Tudo no feminino: a mulher e a narrativa brasileira contemporânea. Rio de Janeiro: Francisco Alves, 1991.

ZOLIN, Lúcia Osana. Literatura de autoria feminina. In: BONNICI, Thomas; ZOLIN, Lúcia Osana, orgs. Teoria literária: abordagens históricas e tendências contemporâneas. 2.ed. Maringá: Eduem, 2005. p. 275-83.

RECEBIDO EM: 07 de maio de 2012

APROVADO EM: 05 de junho de 2012 